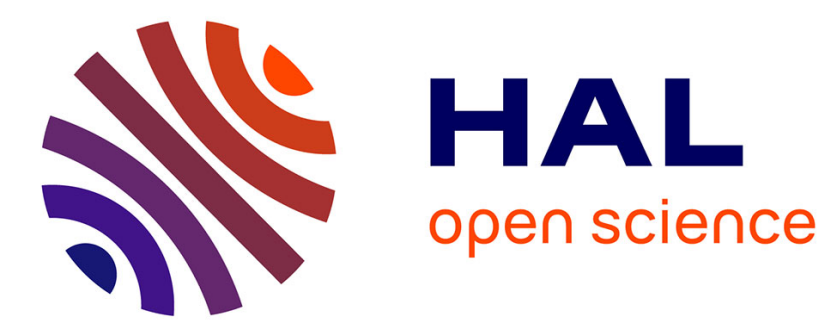

\title{
High temperature mechanical properties of AlMgZn alloys with copper and zirconium additions
}

\author{
N. Chinh, A. Juhász, P. Tasnádi, J. Lendvai, I. Kovács
}

\section{To cite this version:}

N. Chinh, A. Juhász, P. Tasnádi, J. Lendvai, I. Kovács. High temperature mechanical properties of AlMgZn alloys with copper and zirconium additions. Journal de Physique IV Proceedings, 1993, 03 (C7), pp.C7-255-C7-261. 10.1051/jp4:1993741 . jpa-00252159

\section{HAL Id: jpa-00252159 https://hal.science/jpa-00252159}

Submitted on 1 Jan 1993

HAL is a multi-disciplinary open access archive for the deposit and dissemination of scientific research documents, whether they are published or not. The documents may come from teaching and research institutions in France or abroad, or from public or private research centers.
L'archive ouverte pluridisciplinaire HAL, est destinée au dépôt et à la diffusion de documents scientifiques de niveau recherche, publiés ou non, émanant des établissements d'enseignement et de recherche français ou étrangers, des laboratoires publics ou privés. 


\title{
High temperature mechanical properties of AlMgZn alloys with copper and zirconium additions
}

\author{
N.Q. CHINH, A. JUHÁSZ, P. TASNÁDI, J. LENDVAI and I. KOVÁCS \\ Institute for General Physics, Loránd Eötvös University, 1088 Budapest, Múzeum krt 6-8, Hungary
}

\begin{abstract}
High temperature mechanical properties of $\mathrm{AlMgZn}$ alloys grain refined by zirconium were investigated by impression creep and tensile tests. The strain rate sensitivities and activation energies obtained are presented. It has been found that the steady-state impression creep rate is strongly influenced by $\mathrm{Cu}$ and $\mathrm{Zr}$ addition. The simultaneous addition of $\mathrm{Cu}$ and $\mathrm{Zr}$ resulted in fine-grained microstructure due to which the material exhibited superplastic properties at high temperatures. Together with the superplastic behaviour the occurrence of a threshold stress has also been observed.
\end{abstract}

\section{Introduction}

The mechanical properties of metals are strongly influenced by the alloying elements being either in solution or in precipitates. The effect of alloying additions is also significant in the high temperature region where under certain conditions superplastic behaviour can take place. It was shown earlier that medium to high strength $\mathrm{AlZnMg}$ alloys can be made to exhibit superplasticity by the addition of zirconium as a grain refining element [1].

The high temperature creep rate of the metals and alloys can generally be described by the equation:

$$
\dot{\varepsilon}=A \sigma^{n_{*}} \mathrm{e}^{-\frac{\mathrm{Q}_{\mathrm{s}}}{\mathrm{kT}}}
$$

where $A$ is a material parameter and $n_{a}$ and $Q_{a}$ are the apparent stress exponent and the apparent activation enthalpy, respectively $[2,3]$. However, it has recently been proved that in some alloys the superplastic deformation is accompanied by the occurrence of threshold stresses modifying both the activation enthalpy and the stress exponent of the process. In this case in equation (l) the stress must be substituted by an effective stress which is the difference between the applied stress and the threshold stress [4-8]. In the case of superplastic materials it is well known that the curve of the $\ln \sigma-\ln \dot{\varepsilon}$ plot is sigmoidal and consists of three parts. Superplastic properties are observed at medium strain rates (region II) while at low (region I) and high (region III) strain rates the superplastic behaviour disappears [9-12]. In this paper the effect of $\mathrm{Cu}$ and $\mathrm{Zr}$ content on the high temperature mechanical properties as well as on the superplastic behaviour of an AlMgZn alloy is discussed.

\section{Experimental details}

The chemical composition of the alloys investigated is shown in Table I. The alloy samples prepared of 99,99\% purity aluminium were provided by the HUNGALU Engineering and Development Centre, Budapest. After casting the samples were homogenized for 8 hours at $470^{\circ} \mathrm{C}$ in air, and hot extruded to sheets of $10 \times 40 \mathrm{~mm}^{2}$ cross section. The starting temperature of the hot extrusion was $380 \pm 5^{\circ} \mathrm{C}$. For solution treatment the specimens were annealed at $470^{\circ} \mathrm{C}$ for $30 \mathrm{~min}$ and water-quenched to room temperature. Following this treatment fully recrystallized materials were obtained. 


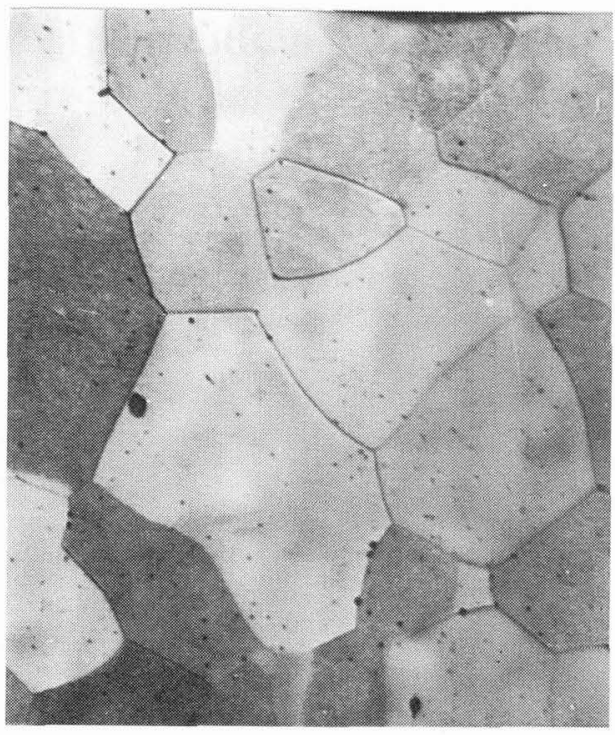

Sample A

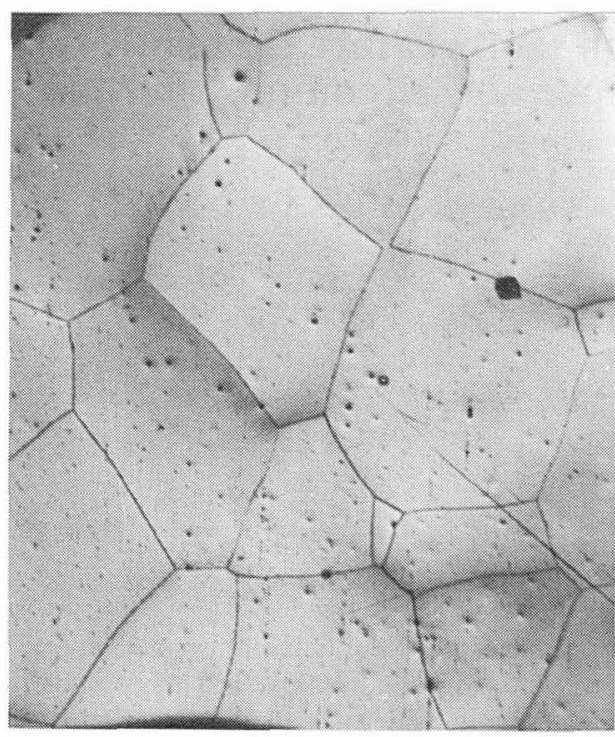

Sample B $100 \mu \mathrm{m}$

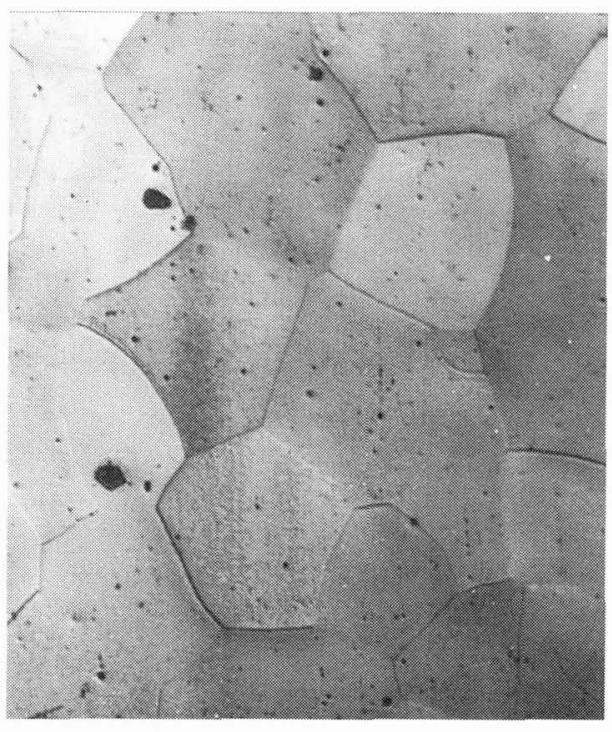

Sample C

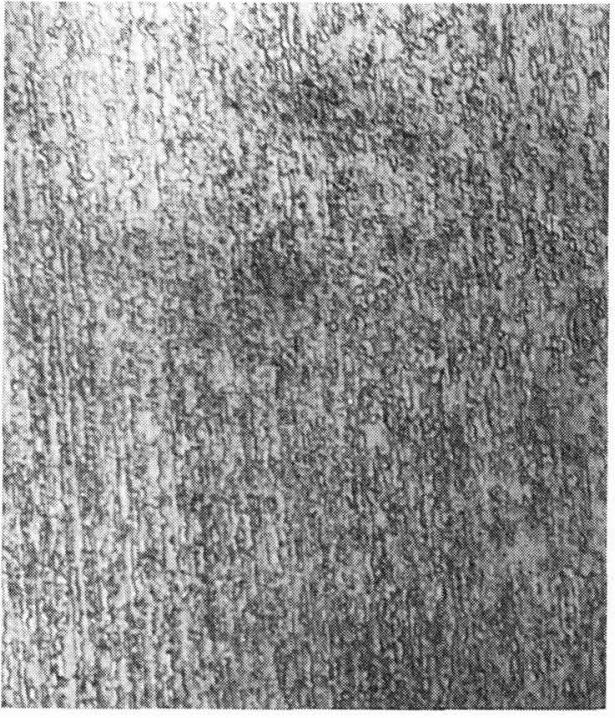

Sample D 


\begin{tabular}{ccccc} 
& \multicolumn{4}{c}{ Alloying elements } \\
Label & $\mathrm{Mg}$ & $\mathrm{Zn}$ & $\mathrm{Cu}$ & $\mathrm{Zr}$ \\
$\mathrm{A}$ & 2.0 & 5.7 & - & - \\
$\mathrm{B}$ & 2.0 & 5.7 & 0.35 & - \\
$\mathrm{C}$ & 1.9 & 5.7 & 1.4 & - \\
$\mathrm{D}$ & 1.9 & 5.7 & 1.4 & 0.12
\end{tabular}

Table I Composition of the alloys (concentrations in wt\%)

The high temperature mechanical properties were studied mainly by impression creep tests and on the basis of the results obtained from these measurements some complementary measurements were made by tensile testing. The detailed descriptions of the creep tester and the method was published previously [13], as well as in this proceeding [14].

The tensile speciments were cylindrical with gauge length of $24 \mathrm{~mm}$. The test were performed by using an INSTRON type machine operating at a constant crosshead velocity in the range from $0.2 \mathrm{~mm} / \mathrm{min}$ to

$20 \mathrm{~mm} / \mathrm{min}$ (initial strain rates $\dot{\varepsilon}_{o}$ were $1.33 \cdot 10^{-4}$ to $1.33 \cdot 10^{-2} \mathrm{sec}^{-1}$ ).

In addition metallographic pictures were taken to show the microstructure of the samples, and SEM pictures were also taken to help understanding the micromechanisms of the superplastic deformation.

\section{Results and discussion}

\subsection{The Impression Creep test}

Fig. 1. shows the microstructure of the samples after quenching. It can be seen that alloys $A, B$ and $C$ with no $\mathrm{Zr}$ addition are fully recrystallized and have very similar coarse grained microstructure with about 100 $\mu \mathrm{m}$ mean grain size. On the contrary, there is a fine grained microstructure in alloy $\mathrm{D}$, where the grains are arranged in bands and the average grain size is about $10 \mu \mathrm{m}$. The occurrence of this fine grained microstructure can be clearly attributed to the grain refining effect of the zirconium.

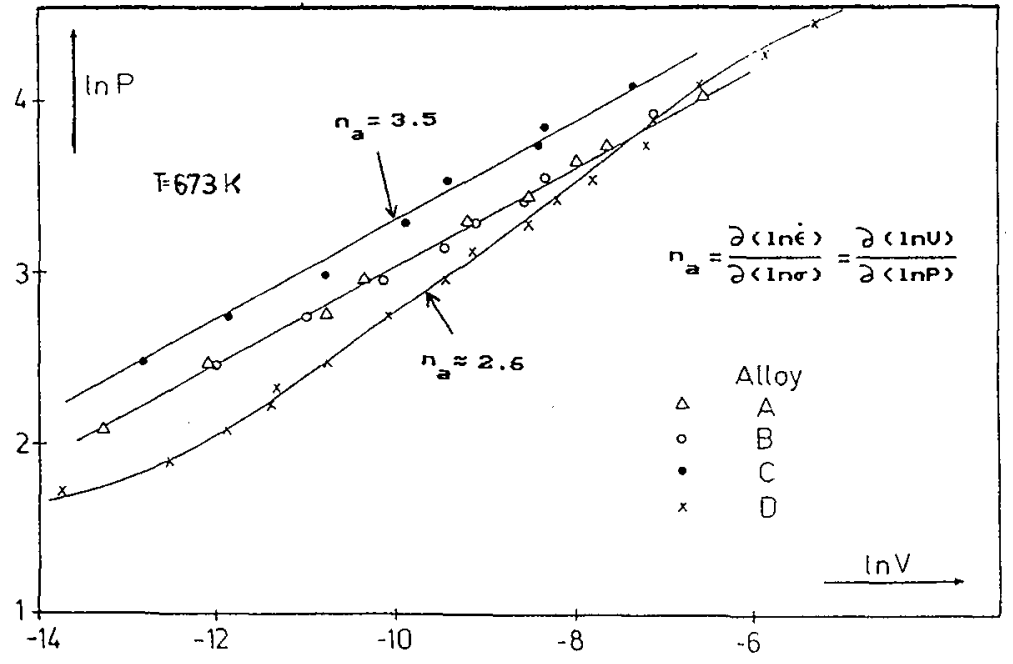

Fig. 2. The double logarithmic plot of the $p, v$ data

Fig 2. shows the double logarithmic plot containing the $p, v$ data measured at 673 $K$ with various loads for the four alloys investigated, where $p$ is the pressure immediately below the indenter and $\mathrm{v}$ is the steady state velocity of the punch during the impression creep test. The curves for material $\mathrm{A}$ and $\mathrm{B}$ coincide giving one straight line with $n_{a}=3.5$ as stress exponent. The line obtained for alloy $\mathrm{C}$ is parallel with that previously described but shifted to somewhat higher $p$ values. This means that although the creep rate is lower (the strength of the material increases due to the higher $\mathrm{Cu}$ content) the stress exponent remains unchanged. The curve for alloy D differs significantly from the curves obtained for the other three alloys. Only the central part of it can be approximated by a straight line. This central section of the curve yields a stress exponent $n_{a}=2.6$. This can be considered as an indication for the superplastic behaviour of alloy $D$ since it is widely accepted that a material can be qualified as superplastic if the strain rate sensitivity, which is the inverse of the stress exponent, is higher than 0.3 [9]. 


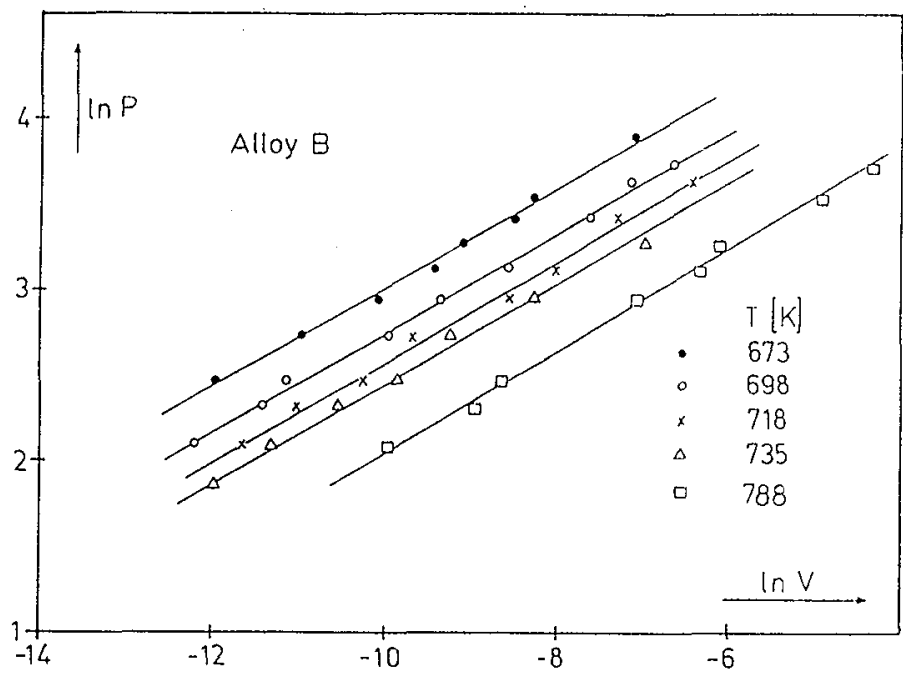

Fig.3. lnp-lnv curves for alloy B

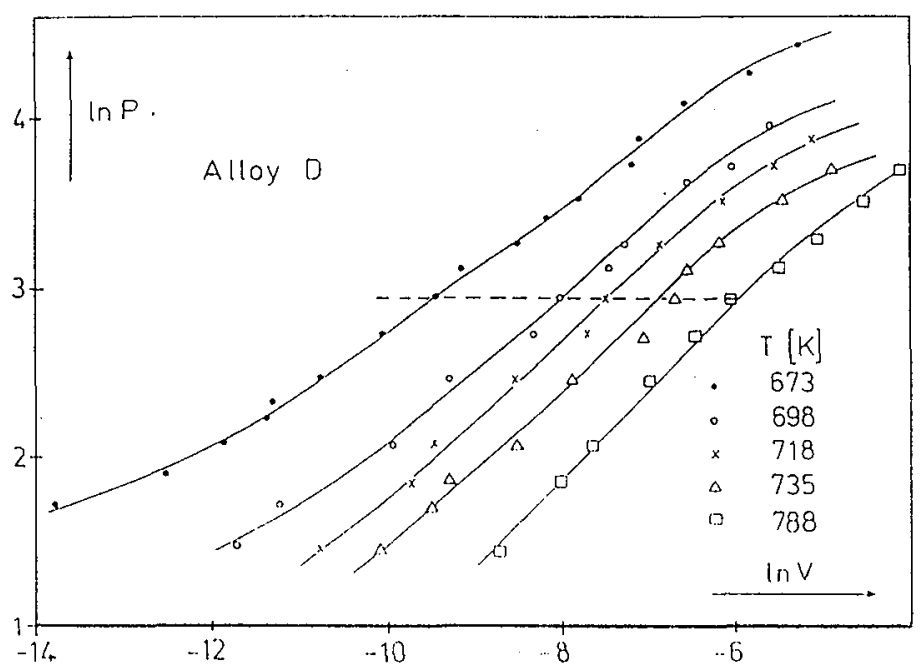

Fig. 4 lnp-lnv curves for alloy D
Fig. 3. and Fig. 4. show the $\operatorname{lnp}-\ln v$ functions obtained at various temperatures for alloy B and D. The curves for alloy $B$ are parallel straight lines. (Similar results were measured also for alloys $A$ and $C$.) The central section of the curves for alloy D - where the deformation can be regarded as superplastic can also be approximated by straight lines which have practically the same slope. Using these approximations and the cross-cut method an apparent activation enthalpy of $130 \mathrm{~kJ} / \mathrm{mol}$ has been determined for the deformation process in the case of alloys A, B and C. This value agrees well with that of the bulk diffusion in Al [15]. The activation entalpy obtained for alloy $D$ is about $170 \mathrm{~kJ} / \mathrm{mol}$. The high activation enthalpy determined for the superplastic region of alloy $D$ seems to be contradictory to the theoretical models predicting that grain boundary sliding controls the superplastic deformation. This contradictions can be resolved however, by introducing an effective stress which is the difference between the applied stress and a threshold stress. According to experimental investigations on superplastic materials the threshold stress exhibits a strong temperature dependence $[16,17]$. As a consequence of this temperature dependence the analysis based on the formula (l) results only in an apparent stress exponent and activation enthalpy. By introducing the threshold stress the following expression is obtained instead of equation (1):

$$
\dot{\varepsilon}=\left(\sigma-\sigma_{0}\right)^{\mathrm{n}} \mathrm{e}^{-\frac{\mathrm{Q}}{\mathrm{kT}}}
$$

where $\sigma_{o}$ is the threshold stress, $\mathrm{n}$ and $\mathrm{Q}$ are the true stress exponent and the true activation enthalpy, respectively. In the case of alloys $\mathrm{A}, \mathrm{B}$ and $\mathrm{C}$ the threshold stress was found to be negligible, so the $\mathrm{n}$ and $Q$ values agree with the $n_{a}$ and $Q_{a}$ values, but in the case of the alloy $D$ the threshold stress must be taken into account. In a previous work [18] we have introduced a method based on equations (2) for the 
determination of the activation entalpy. By this method the corrected (true) activation entalpy of alloy $D$ is obtained as $120 \mathrm{~kJ} / \mathrm{mol}$.

\subsection{The Tensile test}

Tensile tests were performed

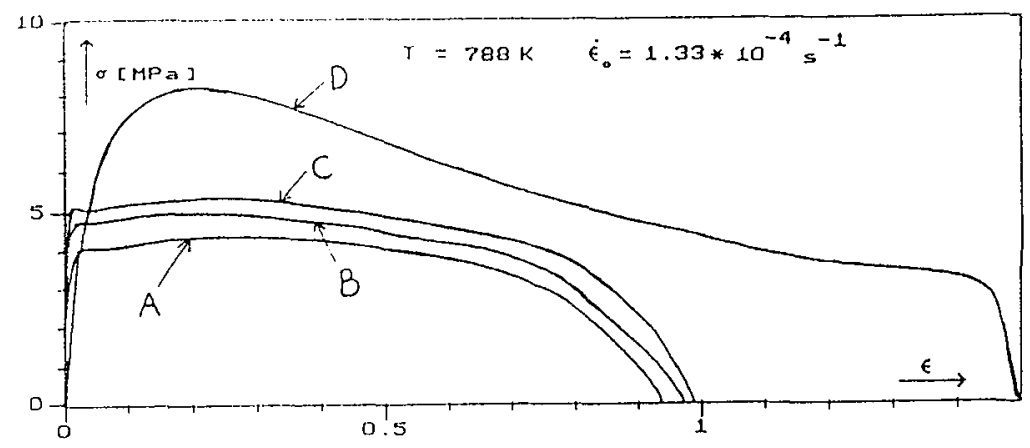

a.

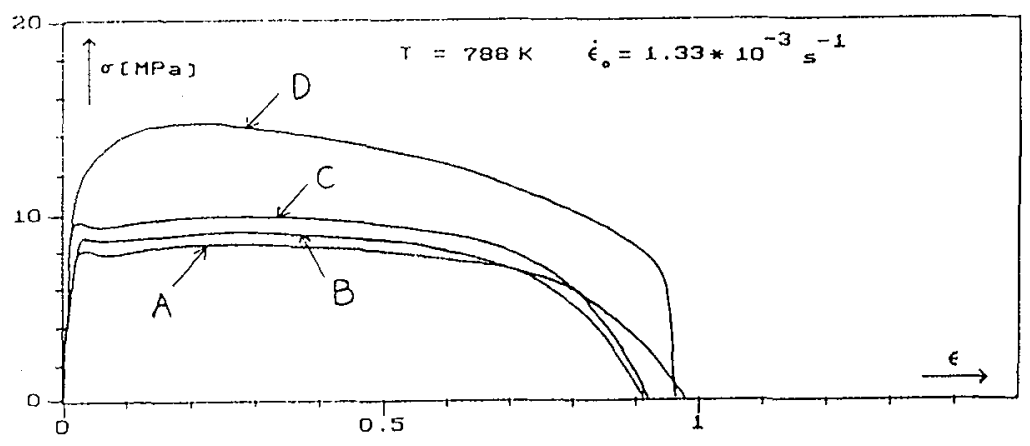

b.

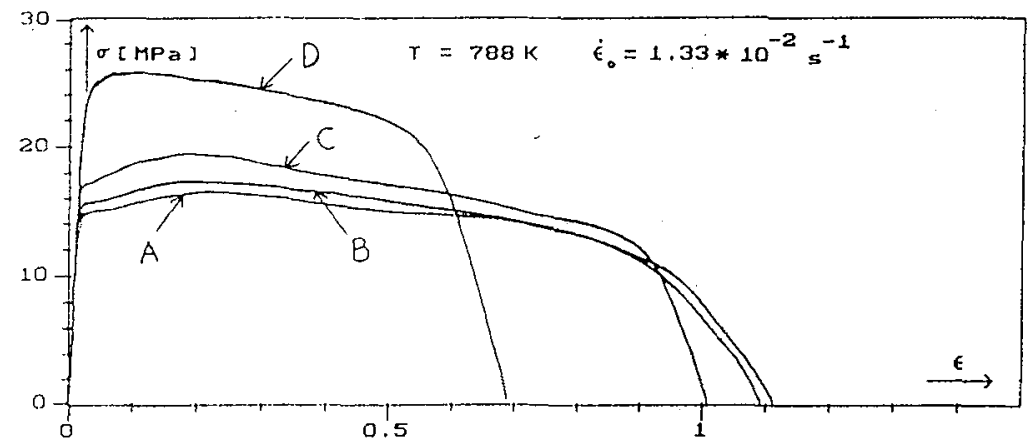

C.

Fig. 5. Stress-strain curves for the alloy investigated at a.) low, b.) medium c) high strain rates at the temperature and strain rate range where on the basis of the impression measurements the behaviour of alloy D was expected to be superplastic. Fig. 5. shows the stress-strain curves obtained at $788 \mathrm{~K}$ with various initial strain rates for the four alloys investigated. It can be seen that in the case of alloys A, B and $C$ at each strain rate the flow stress increases with increasing $\mathrm{Cu}$ content, the total elengations, however, remains constant independently of the strain rate and of the $\mathrm{Cu}$ content. This is in agreement with the observation that the values of the macroscopic paramteres charaterizing the creep process $(n, Q)$ are also independent of the amount of $\mathrm{Cu}$ additions. In contrast to this, in the case of alloy $D$ the total elongation is strongly changing with strain rate, which is a common feature of superplastic materials [10-12]. While at the lowest strain rate the total elongation is larger than 300 $\%$, at the highest rate the sample elongated only 60 per cent. Fig. 6 . shows a sample elongated by 300 per cent. In Fig. 7. the total elongation is shown as a function of the initial strain rate taken at 788 $\mathrm{K}$ for alloy $\mathrm{D}$. The data points on the maximum elongation vs. strain rate curve indicates that these measurements were taken in the strain rate regions II and III.

Fig. 8. is a SEM picture taken from the fracture surface of a

sample deformed superplastically in region II. It can be seen that in region II the sample failed along grain bounderies, which confirms that in this region grain boundary sliding yields the major contribution to the deformation. 


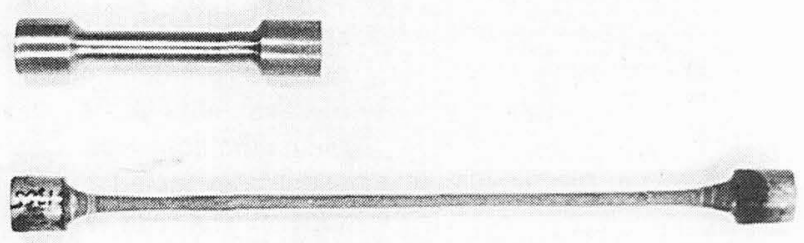

Fig.6. Sample with total elongation of $300 \%$

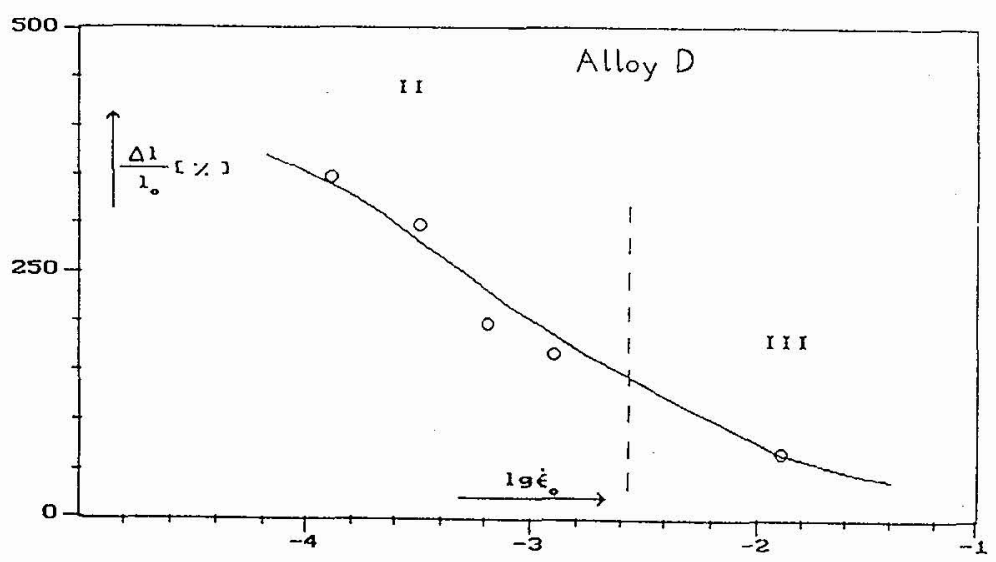

Fig. 7.Maximum elongation versus initial strain rate

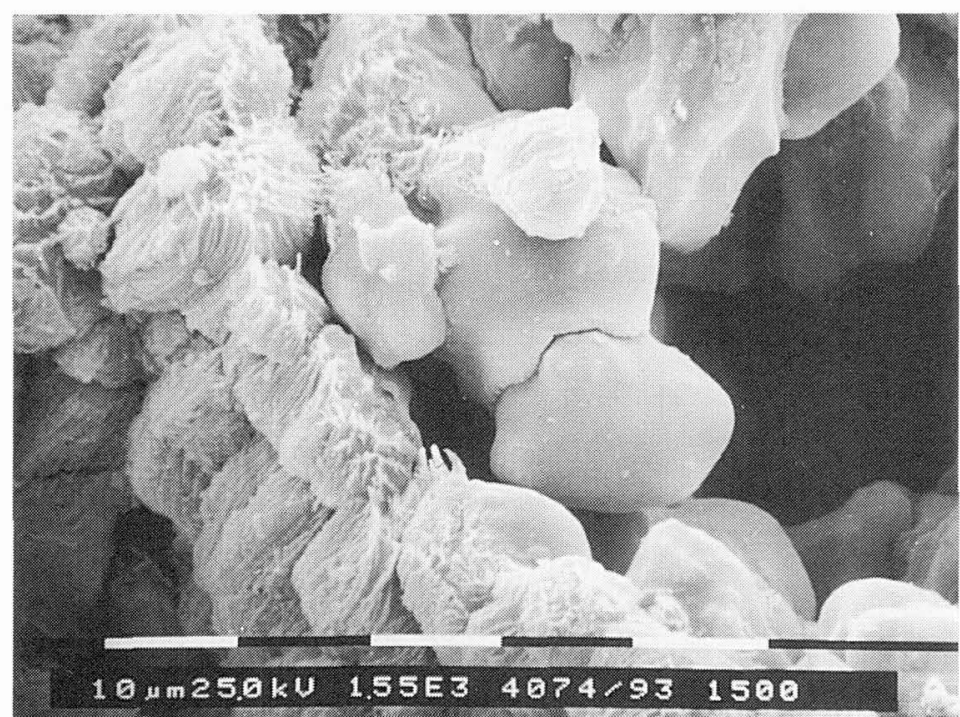

Fig.8. The fracture surface of a superplastically deformed sample

\section{Conclusions}

1. It was shown that the high temperature strength of the AlMgZn alloy studied here is considerably increased by the additions of $\mathrm{Cu}$.

2 . In the case of the alloys without $\mathrm{Zr}$ the values of the macroscopic parameters ( $\mathrm{n}$, Q) characterizing the deformation are independent of the $\mathrm{Cu}$ content. From the $\mathrm{Q}=130 \mathrm{~kJ} / \mathrm{mol}$ and the $n=3.5$ values it can be concluded that in these alloys dislocation creep is the main mechanism of deformation.

3. A strong grain refining effect can be established by adding $0,12 \% \quad$ zirconium together with copper, which caused the deformation of the alloy to be superplastic in the temperature range of 400-515 ${ }^{\circ} \mathrm{C}$ at strain rates of $5 \cdot 10^{-6}$ $2.5 \cdot 10^{-3} \mathrm{l} / \mathrm{s}$.

4. The superplastic processes were accompanied by the occurrence of a strongly temperature dependent threshold stress which led to an exceptionally high value of the apparent activation enthalpy. By taking into account the temperature dependence of the threshold stress a more realistic value of the activation enthalpy has been determined which was close to that of the bulk diffusion of the alloy.

5. The SEM investigation of the fracture surface of superplastically deformed fine grained alloy D samples indicated also that in this case grain boundary sliding is the main mechanism of the superplastic deformation.

Acknowledgement

The authors are grateful to the Hungarian National Scientific Research Fund for their financial support of this research under contract number OTKA-2187. 


\section{References}

[1] Juhász A., Chinh N. Q., Tasnádi P., Kovács I. and Turmezey T., J. Mater. Sci. 22 (1987) 137-143.

[2] Mukherjee A. K., Plastic Deformation of Materials, ed. Arsenault D. J., (Acad. Press, New York, 1975) pp. 163-217.

[3] Oikawa, H. and Langdon T. G., Creep Behaviour of Crystalline Solids, eds. Wilshire B. and Evans R. W., (Pineridge Press, Swansea, UK., 1985) pp. 33-82.

[4] Mohamed F. A., J. Mater. Sci. 18 (1983) 582-594.

[5] Murty G. S.and Koczak M. J., J. Mater. Sci. 24 (1989) 510-514.

[6] Chinh N. Q.,Juhász A., Tasnádi P.and Kovács I., J. Mater. Sci. 25 (1990) 4767-4771.

[7] Langdon T. G., Mater. Sci. Eng. A137 (1991) 1-11.

[8] Malek P., ibid., pp. 21-26.

[9] Edington I. W., Melton N. K. and Cutler P., Prog. Mat. Sci. 21 (1976) pp. 61-158.

[10] Dunlop G. L. and Taplin D. M. R., J. Mater. Sci. 7 (1972) 84-92.

[11] Shakesheff A. I. and Partridge P. G., J. Mater. Sci. 20 (1985) 2408-2416.

[12] Chokshi A., H. and Langdon T. G., Mater. Sci. Techn. 5 (1989) 435-442.

[13] Juhász A., Chinh N. Q., Tasnádi P., Kovács I. and Turmezey T., Mater. Sci. Forum, 13/14 (1987) 429-434.

[14] Chinh N. Q., Juhász A., Tasnádi P. and Kovács I., in this volume

[15] Varostos P. A. and Alexopoulos, Thermodynamics of Point Defects and Their Relation with Bulk Properties (North - Holland, Amsterdam, 1986) p. 313.

[16] Mohamed F. A., J. Mater. Sci. Lett., 7 (1989) pp. 215-217.

[17] Mc Lane ; Acta Met., 33 (1985) 545-556.

[18] Chinh N. Q., Tasnádi P., Juhász A. and Kovács I., submitted to J. Mater. Sci. 